\title{
Measurement of 3-Hydroxyanthranilic Acid and Anthranilic Acid in Urine by High-performance Liquid Chromatography
}

\author{
Katsumi Shibata and Michiko OnODERA \\ Department of Food Science and Nutrition, Teikoku Women's University, \\ Moriguchi, Osaka 570, Japan \\ Received July 9, 1990
}

\begin{abstract}
Measurements of 3-hydroxyanthranilic acid and anthranilic acid in urine are described. The urine adjusted to $\mathrm{pH} 3.0$ was saturated with $\mathrm{NaCl}$, and 3-hydroxyanthranilic acid and anthranilic acid were extracted with diethyl ether. The method for 3-hydroxyanthranilic acid measurement employed a Shim-pack CLC-ODS $(150 \mathrm{~mm} \times 6.0 \mathrm{~mm}$ i.d.) column eluted with $100 \mathrm{~mm}$ potassium dihydrogenphosphate (pH 4.5)-acetonitrile $(9: 1, \mathrm{v} / \mathrm{v})$ at a flow rate of $1.5 \mathrm{ml} / \mathrm{min}$. The applied volage was set at $+300 \mathrm{mV} v s$. $\mathrm{Ag} / \mathrm{AgCl}$, the detection limit being $0.2 \mathrm{pmol}(30.62 \mathrm{pg})$ at a signal-to-noise ratio of 5:1. The method for anthranilic acid measurement employed a Chemcosorb 5-ODS-H $(150 \mathrm{~mm} \times 4.6 \mathrm{~mm}$ i.d.) column eluted with $80 \mathrm{~mm}$ potassium dihydrogenphosphate ( $\mathrm{pH}$ adjusted to 3.0 by phosphoric acid)-acetonitrile $(65: 35, \mathrm{v} / \mathrm{v})$ at a flow rate of $1.0 \mathrm{ml} / \mathrm{min}$, with estimation at an excitation wavelength of $340 \mathrm{~nm}$ and an emission wavelength of $410 \mathrm{~nm}$. The detection limit was $0.3 \mathrm{pmol}(41.13 \mathrm{pg})$ at a signal-to-noise ratio of $5: 1$. These techniques were applied to the analyses of riboflavin-deficient rat urine. The total analysis times for 3-hydroxyanthranilic acid and anthranilic acid were ca. $12 \mathrm{~min}$ and $7 \mathrm{~min}$, respectively.
\end{abstract}

The investigation of tryptophan metabolism has interested many investigators because it is influenced by a large number of factors; e.g., vitamins status, ${ }^{1)}$ Hartnup disease, ${ }^{2)}$ congenital tryptophanuria with dwarfism, ${ }^{3)}$ depression, ${ }^{4)}$ schizophrenia, ${ }^{5}$ and carcinoid tumors. ${ }^{6)}$ In investigating the metabolic fate of tryptophan, the establishment of reliable determination methods is very important. We have already reported the high-performance liquid chromatographic measurements of serotonin, ${ }^{7)} 5$ hydroxyindole-3-acetic acid, ${ }^{7}$ kynurenic acid, ${ }^{8)}$ nicotinamide $^{9)}$ and its metabolites. ${ }^{10-14)}$

It is known that riboflavin involves the reaction kynurenine $\rightarrow 3$-hydroxykynurenine ${ }^{15}$ ) and that riboflavin deficiency therefore results in greater excretion of anthranilic acid and kynurenic acid, ${ }^{16)}$ with decreased excretion of the metabolites beyond 3-hydroxykynurenine such as 3-hydroxyanthranilic acid (Fig. 1). ${ }^{17}$ However, precise values for the spontaneous excretion of anthranilic acid and 3-hydroxyanthranilic acid are not known. Therefore, the establishment of determination methods for anthranilic acid and 3-hydroxyanthranilic acid is important. As reported by Van Der Poll et $a l .,{ }^{18)}$ there are several methods for determining the urinary contents of anthranilic acid and 3-hydroxyanthranilic acid; ${ }^{19-23)}$ however, most of them lack specificity and/or high sensitivity. Namely, these methods cannot be applied for measuring the spontaneous excretion of 3-hydroxyanthranilic acid and anthranilic acid. Van Der Poll et al. ${ }^{18)}$ have reported a reliable gas chromatographic analysis of 3-hydroxyanthranilic acid and anthranilic acid; however, its derivatization and cleaning processes for gas chromatography

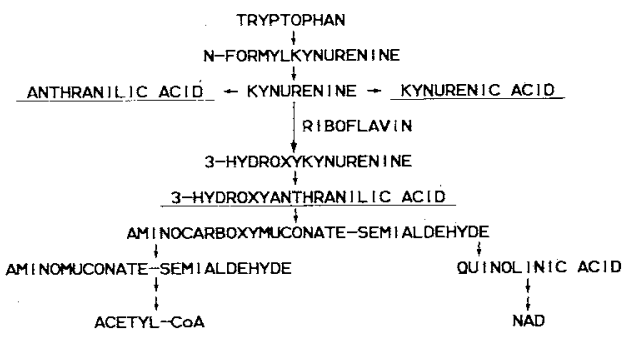

Fig. 1. Tryptophan-Kynurenine Metabolism. 
are time-consuming. We therefore developed an HPLC analysis method for these acids, and also investigated how the urinary excretion of 3-hydroxyanthranilic acid, anthranilic acid, and kynurenic acid would change when rats were fed with a riboflavin-free diet.

\section{Materials and Methods}

Chemicals. 3-Hydroxyanthranilic acid was purchased from Tokyo Kasei Kogyo (Tokyo, Japan). Anthranilic acid was obtained from Wako (Osaka, Japan). All the other chemicals used were of the highest commercial grade available. The standard solution of 3-hydroxyanthranilic acid $(10 \mu \mathrm{M})$ in methanol was stable for at least 1 month at $4^{\circ} \mathrm{C}$ and $-25^{\circ} \mathrm{C}$, respectively. The standard solution of anthranilic acid $(10 \mu \mathrm{M})$ in methanol was stable for at least 1 month at room temperature, $4^{\circ} \mathrm{C}$ and $-25^{\circ} \mathrm{C}$, respectively. The concentrations of 3-hydroxyanthranilic acid and anthranilic acid in methanol were calculated by using values for the molar absorptivity of $3860 \mathrm{M}^{-1} \cdot \mathrm{cm}^{-1}$ at $340 \mathrm{~nm}$ and $3990 \mathrm{M}^{-1} \cdot \mathrm{cm}^{-1}$ at $333 \mathrm{~nm}$, respectively.

Analyses.

3-Hydroxyanthranilic acid. The apparatus employed consisted of a liquid chromatograph P-530 (Irica Instruments, Kyoto, Japan), a Model 7125 syringe-loading injector (Rheodyne, Cotati, CA, U.S.A.), a Shim-Pack CLC-ODS column $(150 \mathrm{~mm} \times 6.0 \mathrm{~mm}$ i.d., Shimadzu, Kyoto, Japan) and an Irica E-502 amperometric detector with a glassy carbon electrode. The mobile phase was a mixture of a degassed solution of $100 \mathrm{~mm}$ potassium dihydrogenphosphate $(\mathrm{pH} 4.5)$-acetonitrile $(9: 1, \mathrm{v} / \mathrm{v})$ and was used at a flow-rate of $1.5 \mathrm{ml} / \mathrm{min}$. The column temperature was maintained at $25^{\circ} \mathrm{C}$. The applied voltage was set at $+300 \mathrm{mV}$ vs. $\mathrm{Ag} / \mathrm{AgCl}$. The HPLC system was interfaced with a Shimadzu Chromatopac C-R6A for data processing.

Anthranilic acid. The apparatus employed consisted of a Shimadzu LC-4A with a Shimadzu RF-540 spectrofluorophotometer, equipped with an LC flow-cell unit, a Model 7125 syringe-loading injector, and a 5-ODS-H column $(150 \mathrm{~mm} \times 4.6 \mathrm{~mm}$ i.d., Chemco Scientific, Osaka, Japan). The mobile phase was a mixture of a degassed solution of $80 \mathrm{~mm}$ potassium dihydrogenphosphate $(\mathrm{pH}$ adjusted to 3.0 by the addition of phosphoric acid)-acetonitrile $(65: 35, \mathrm{v} / \mathrm{v})$ and was used at a flow-rate of $1.0 \mathrm{ml} / \mathrm{min}$. The column temperature was maintained at $25^{\circ} \mathrm{C}$. Anthranilic acid was measured at an excitation wavelength of $340 \mathrm{~nm}$ (10-nm bandpass) and at an emission wavelength of $410 \mathrm{~nm}$ (10-nm bandpass). The HPLC system was interfaced with a Shimadzu Chromatopac C-R3A for data processing.

Kynurenic acid. The kynurenic acid in urine was measured by the HPLC method of Shibata. ${ }^{8}$
Table I. COMPOSITION OF THE RibOFLAVIN-FREE DIET

$\mathrm{g} / \mathrm{kg}$ of diet

$\begin{array}{lr}\text { Vitamin-free milk casein }^{a} & 200 \\ \text { L-Methionine }^{a} & 2 \\ \alpha \text {-Cornstarch }^{b} & 458 \\ \text { Sucrose }^{a} & 230 \\ \text { Corn oil }^{c} & 50 \\ \text { Mineral mixture }^{d} & 50 \\ \text { Vitamin mixture }^{e} \text { (Riboflavin-free) } & 10\end{array}$

a Obtained from Wako Pure Chemical Industries (Osaka, Japan).

$b$ Obtained from Nichiden Kagaku Co. (Tokyo Japan).

c Obtained from Nippon Shokuhin Kako Co. (Tokyo, Japan).

d The composition (Oriental's ratio) is described in ref. 27. Obtained from the Oriental Yeast Kogyo Co. (Tokyo, Japan).

- The composition (Oriental's ratio with riboflavin omitted) is described in ref. 27. Obtained from the Oriental Yeast Kogyo Co.

$20 \%$ Casein diet: $1 \mathrm{~kg}$ of riboflavin-free $20 \%$ casein +40 $\mathrm{mg}$ of riboflavin.

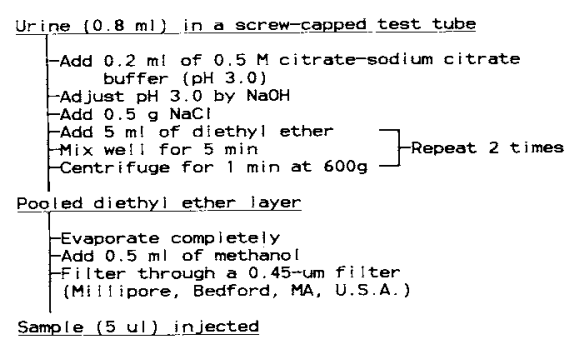

Fig. 2. Procedure for Extracting 3-Hydroxyanthranilic Acid and Anthranilic Acid from Urine.

Animal experiments. Male rats of the Wistar strain (3 weeks old) were purchased from Clea Japan Inc. (Tokyo, Japan). The rats were placed in individual metabolic cages (CT-10; obtained from Clea Japan) upon arrival, and fed with a $20 \%$ casein diet (Table I) or a riboflavin-free $20 \%$ casein diet (Table I) ad libitum for 80 days. Urine samples were collected in amber bottles containing $1 \mathrm{ml}$ of $1 \mathrm{M} \mathrm{HCl}$ from the last day of the experiment $(09: 00$ on the 80 th day to $09: 00$ on the 81 st day), diluted with $0.1 \mathrm{M} \mathrm{HCl}$ to make up to $50 \mathrm{ml}$ per day and stored at $-25^{\circ} \mathrm{C}$ until analysed. Van Der Poll et al. ${ }^{18}$ ) have reported that 3-hydroxyanthranilic acid and anthranilic acid in urine were stable for at least 1 month at $-20^{\circ} \mathrm{C}$, so the measurements was taken within 1 month.

The room temperature was kept at $22 \pm 2^{\circ} \mathrm{C}$, the humidity being about $60 \%$, and a 12-hr light/dark cycle was maintained. The body weight and food intake were measured daily at around $09: 00 \mathrm{hr}$, and food and water 
were renewed daily.

Extraction of 3-hydroxyanthranilic acid and anthranilic acid from urine. The procedure for extracting 3-hydroxyanthranilic acid and anthranilic acid from urine reported by Van Der Pool et al. ${ }^{18)}$ was modified as shown in Fig. 2.

\section{Results and Discussion}

\section{Extraction}

A mixture of standard 3-hydroxyanthranilic acid and anthranilic acid was stoichiometrically transferred into the diethyl ether layer when the $\mathrm{pH}$ of the mixture had been adjusted to 3 as reported by Van Der Poll et al. ${ }^{18)}$ However, the percentages of extractable 3-hydroxyanthranilic acid and anthranilic acid were extremely low when the $\mathrm{pH}$ of the mixture was adjusted to 1 (around 14\% for both acids) and 12 (around $0.3 \%$ for both acids).

\section{Detection methods}

3-Hydroxyanthranilic acid. 3-Hydroxyanthranilic acid was measured by the amperometric method because the sensitivity was higher than by the fluorimetric and UV methods. The highest response was obtained at around $+300 \mathrm{mV}$ vs. $\mathrm{Ag} / \mathrm{AgCl}$ under the conditions shown in Fig. 3. Consequently, the applied voltage was set at $+300 \mathrm{mV}$.

Anthranilic acid. Anthranilic acid was measured by the fluorimetric method because the sensitivity was higher than by the UV method. Anthranilic acid was amperometrically inactive. The excitation and emission spectra of anthranilic acid on-line are shown in Fig. 4. The highest sensitivity was obtained when anthranilic acid was estimated at an excitation wavelength of $340 \mathrm{~nm}$ and an emission wavelength of $410 \mathrm{~nm}$.

\section{Calibration curves and limits of detection}

3-Hydroxyanthranilic acid. The calibration curve for 3-hydroxyanthranilic acid was linear in the range of $0.2-500 \mathrm{pmol}$ per injection. The relative standard deviation of the peak area of 3 -hydroxyanthranilic acid (10 pmol per injection; five injections) was less than $1 \%$. The

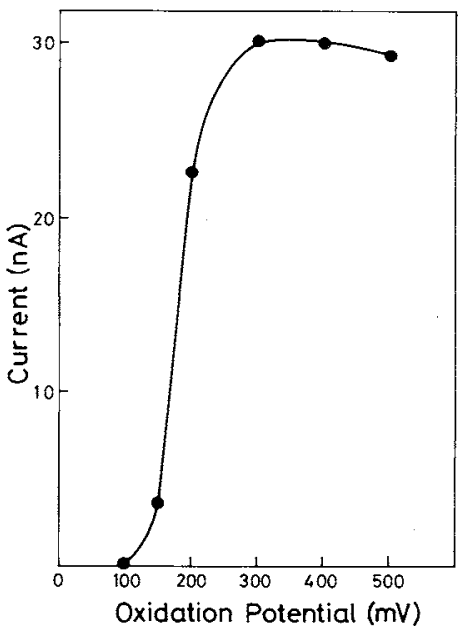

Fig. 3. Voltammogram for 3-Hydroxyanthranilic Acid. HPLC conditions are as described in the analysis section except for the applied voltage; 50 pmol of the reference 3-hydroxyanthranilic acid in methanol was injected.

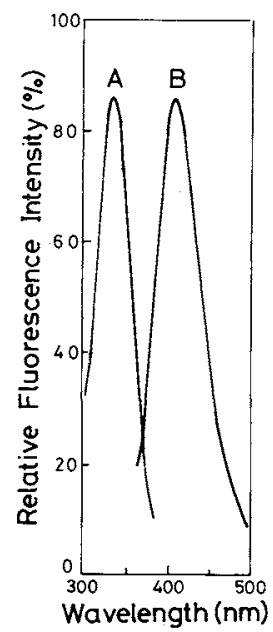

Fig. 4. Excitation (A) and Emission (B) Spectra of the Anthranilic Acid Peak by Stopped-flow and Scanning Modes.

The HPLC conditions are as described in the analysis section except for the excitation and emission wavelengths. The excitation spectrum was obtained with an emission wavelength of $410 \mathrm{~nm}$, and the emission spectrum was obtained with an excitation wavelength of $340 \mathrm{~nm}$.

detection limit was $0.2 \mathrm{pmol}(30.62 \mathrm{pg})$ at a signal-to-noise ratio of $5: 1$.

Anthranilic acid. The calibration curve for anthranilic acid was linear in the range of $0.3-500$ pmol per injection. The relative stan- 
Table II. Precision and Analytical Recovery of 3-Hydroxyanthranilic Acid (3-HA) ANd ANthranilic Acid (AnA) Added to Rat Urine

\begin{tabular}{|c|c|c|c|c|c|}
\hline \multicolumn{2}{|c|}{ Added } & \multicolumn{2}{|c|}{ Found } & \multicolumn{2}{|c|}{ Recovery } \\
\hline $\begin{array}{l}\text { 3-HA } \\
(\mathrm{nmol})\end{array}$ & $\begin{array}{c}\text { AnA } \\
\text { (nmol) }\end{array}$ & $\begin{array}{c}\text { 3-HA } \\
(\mathrm{nmol})\end{array}$ & $\begin{array}{c}\text { AnA } \\
(\mathrm{nmol})\end{array}$ & $\begin{array}{c}3-\mathrm{HA} \\
(\%)\end{array}$ & $\begin{array}{l}\text { AnA } \\
(\%)\end{array}$ \\
\hline 0 & 0 & $\begin{array}{l}0.648 \pm 0.022 \\
(\text { C.V. }=3.4 \%)\end{array}$ & $\begin{array}{l}2.968 \pm 0.062 \\
\text { (C.V. }=2.1 \%)\end{array}$ & - & - \\
\hline $10^{a}$ & $10^{b}$ & $\begin{array}{r}10.232 \pm 0.159 \\
\text { C.V. }=1.5 \% \text { ) }\end{array}$ & $\begin{array}{r}12.872 \pm 0.148 \\
(\mathrm{C} . \mathrm{V} .=1.1 \%)\end{array}$ & $95.8^{c}$ & $99.0^{d}$ \\
\hline
\end{tabular}

Values are means $\pm S D$ for five experiments.

a A 10- $\mu$ sample of $1 \mathrm{~mm}$ 3-hydroxyanthranilic acid $(10 \mathrm{nmol})$ was added to $0.8 \mathrm{ml}$ of rat urine.

b A $10-\mu \mathrm{l}$ sample of $1 \mathrm{~mm}$ anthranilic acid $(10 \mathrm{nmol})$ was added to $0.8 \mathrm{ml}$ of rat urine.

c $(10.232-0.648) / 10 \times 100=95.8 \%$.

d $(12.872-2.968) / 10 \times 100=99.0 \%$.

dard deviation of the peak area of anthranilic acid ( 10 pmol per injection; five injections) was less than $1 \%$. The detection limit was $0.3 \mathrm{pmol}$ $(41.13 \mathrm{pg})$ at a signal-to-noise ratio of $5: 1$.

\section{Precision and recovery of 3-hydroxyanthranilic acid and anthranilic acid from rat urine}

In order to determine the precision of the method, a pooled rat urine sample was analysed five times. As shown in Table II, the coefficient of variation (C. V.) was very low, indicating that the reproducibility of this method was very high. A $10 \mu \mathrm{l}$ volume of $1 \mathrm{~mm}$ 3-hydroxyanthranilic acid and $10 \mu \mathrm{l}$ of $1 \mathrm{~mm}$ anthranilic acid were added to $0.8 \mathrm{ml}$ of the urine sample and processed as described in Fig. 2. The recoveries of the added 3-hydroxyanthranilic acid and anthranilic acid from rat urine were satisfactory as shown in Table II.

\section{Application of the method}

There are no reports on the values for 3-hydroxyanthranilic acid and anthranilic acid in rat urine, although there are some reports of the figures for human urine. ${ }^{18,24,25)}$ So the urinary excretion of 3-hydroxyanthranilic acid and anthranilic acid in rats fed with a $20 \%$ casein diet and with a riboflavin-free $20 \%$ casein diet were measured. The urinary excretion of kynurenic acid was also measured to learn how tryptophan metabolism would change when rats were fed with the riboflavin-
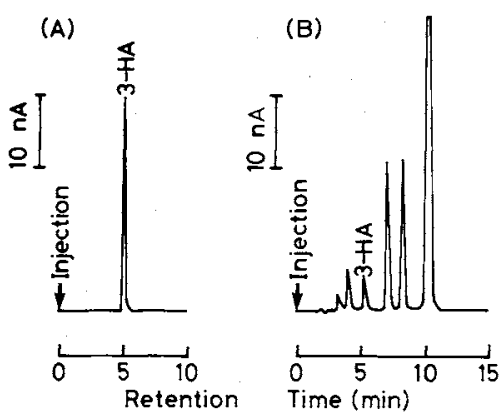

Fig. 5. (A) Chromatogram of Standard 3-Hydroxyanthranilic Acid (3-HA, $50 \mathrm{pmol}$ ). (B) Chromatogram of an Extract of Riboflavin-Deficient Rat Urine.

The sample size was $5 \mu 1$ containing 9.4 pmol of $3-$ hydroxyanthranilic acid. For the HPLC conditions, see the analysis section.

free diet.

The chromatogram of the reference 3hydroxyanthranilic acid is shown in Fig. 5A, 3-Hydroxyanthranilic acid being eluted at $c a$. $5.2 \mathrm{~min}$. The chromatogram of the extract of a urine sample from a riboflavin-deficient rat is shown in Fig. 5B, the chromatogram being essentially the same in the econtrol rats. 3-Hydroxyanthranilic acid in the sample was characterized on the basis of its retention time, the total HPLC analysis time being $c a .12 \mathrm{~min}$. The content of 3-hydroxyanthranilic acid excretion in the control and riboflavin-deficient rats is given in Table III. 3-Hydroxyanthranilic acid excretion in terms of daily urine was 
Table III. URINARY EXCRETION OF 3-Hydroxyanthranilic ACID, ANTHRANILIC ACID, AND KyNURENIC ACID In Rats FED WITH A 20\% CASEIN (CONTROL) AND A RibOFLAVIN-FREE 20\% CASEIN DieTs

Male rats of the Wistar strain [3 weeks old; body weight, $41 \pm 2 \mathrm{~g}$ (control diet group), $40 \pm 1 \mathrm{~g}$ (riboflavinfree diet group)] were fed with a $20 \%$ casein diet (control) or a riboflavin-free $20 \%$ casein diet ad libitum for 80 days. Urine samples were collected on the last day of the experiment.

\begin{tabular}{|c|c|c|}
\hline & Control & Riboflavin-free \\
\hline \multicolumn{3}{|c|}{ Body weight on the last day of the experiment (g) } \\
\hline & $339 \pm 9^{a}$ & $100 \pm 5^{b}$ \\
\hline \multicolumn{3}{|c|}{ Food intake during urine collection period ( $\mathrm{g} /$ day) } \\
\hline & $14.7 \pm 1.7^{a}$ & $7.5 \pm 0.7^{b} \quad(51 \%)$ \\
\hline \multicolumn{3}{|c|}{ 3-Hyroxyanthranilic acid } \\
\hline (nmol/daily urine) & $50.9 \pm 1.9^{a}$ & $34.1 \pm 3.5^{b} \quad(68 \%)$ \\
\hline (nmol/g food) & $3.6 \pm 0.5$ & $4.6 \pm 0.6$ \\
\hline \multicolumn{3}{|l|}{ Anthranilic acid } \\
\hline (nmol/daily urine) & $53.3 \pm 8.5^{a}$ & $144.0 \pm 13.6^{b}(270 \%)$ \\
\hline (nmol/g food) & $3.5 \pm 0.5^{a}$ & $19.1 \pm 1.8^{b} \quad(546 \%)$ \\
\hline \multicolumn{3}{|l|}{ Kynurenic acid } \\
\hline (nmol/daily urine) & $1231 \pm 168$ & $1174 \pm 161 \quad(95 \%)$ \\
\hline$(\mathrm{nmol} / \mathrm{g}$ food) & $80.4 \pm 6.0^{a}$ & $155.9 \pm 22.6^{b}(194 \%)$ \\
\hline$(\mathrm{KA}+\mathrm{AnA}) / 3-\mathrm{HA}^{* 1}$ & $26.6 \pm 3.6^{a}$ & $37.3 \pm 5.0^{b} \quad(140 \%)$ \\
\hline
\end{tabular}

Values are means $\pm S E M$ for five rats; values with a different superscript letter in the same row are statistically significantly different at $p<0.05$ as determined by Student's $t$ test. $^{28)}$

*1 (Kynurenic acid + Anthranilic acid)/3-Hydroxyanthranilic acid.

statistically significantly lower in the riboflavindeficient rats than in the control rats; however, that in terms of the food intake should no difference between the two groups. This result means that the riboflavin-deficiency state was not particularly severe, although the growth of the rats fed with the riboflavin-free $20 \%$ casein diet was statistically significantly lower than those fed with the $20 \%$ casein diet (Table III).

A typical chromatogram of the reference anthranilic acid is shown in Fig. 6A, anthranilic acid being eluted at $c a .4 \mathrm{~min}$. In this connection, 3-hydroxyanthranilic acid was eluted at $c a .2 .6 \mathrm{~min}$. The chromatogram of the extract of a urine sample from a riboflavindeficient rat is shown in Fig. 6B, the chromatogram being essentially the same in the control rats. Anthranilic acid in the sample was

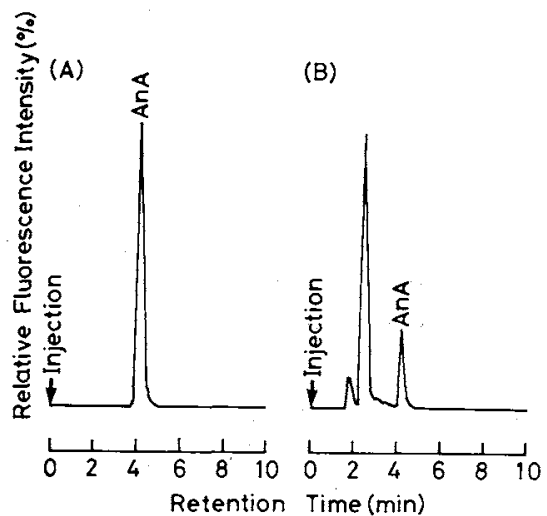

Fig. 6. (A) Chromatogram of Standard Anthranilic Acid (AnA, $50 \mathrm{pmol}$ ) from a Shimadzu Chromatopac C-R3A at Attenuation Level 5. (B) Chromatogram of an Extract of Riboflavin-deficient Rat Urine.

The sample size was $5 \mu$ l containing 15.2 pmol of anthranilic acid run on a Shimadzu Chromatopac C-R3A at attenuation level 5. For the HPLC conditions, see, the analytical section.

characterized on the basis of its retention time and the entire excitation and emission spectra between 300 and $500 \mathrm{~nm}$. The total analysis time was ca. $7 \mathrm{~min}$. The content of anthranilic acid excretion in the control and riboflavindeficient rats is given in Table III. The anthranilic acid excretion was statistically significantly higher in the riboflavin-deficient rats than in the control rats when the value is expressed in terms of daily urine as well as in terms of food intake. This is considered to be the result of a decrease in the reaction of Kynurenine $\rightarrow$ 3-hydroxykynurenine; that is, the reaction of kynurenine $\rightarrow$ anthranilic acid was accelerated.

The urinary excretion of kynurenic acid, which is also a tryptophan metabolite (see Fig. 1), is given in Table III. Kynurenic acid excretion in terms of daily urine did not vary between the two groups; however, that in terms of food intake was statistically significantly higher in the riboflavin-deficient rats than in the control rats. This is also considered to be the result of a decrease in the kynurenine $\rightarrow$ 3-hydroxykynurenine reaction (see Fig. 1).

When animals are riboflavin-deficient, the percentages of anthranilic acid and kynurenic 
acid formation from tryptophan increase, and the percentages of the metabolites beyond 3-hydroxykynurenine decrease as a result of a decrease in the kynurenine $\rightarrow 3$-hydroxykynurenine reaction (Fig. 1). The excretion ratio of (kynurenic acid + anthranilic acid)/3-hydroxyanthranilic acid would be a usable index of the riboflavin-deficient state. This excretion ratio was 26.6 in the control rats and 37.3 in the riboflavin-deficient rats, thus being significantly higher in the riboflavin-deficient rats than in the control rats.

3-Hydroxyanthranilic acid and anthranilic acid are also excreted into urine in the conjugated forms of 3-hydroxyanthranilate glucuronide and anthranilate glucuronide. ${ }^{26)}$ Van der Poll et al. ${ }^{18)}$ reported that these glucuronides can be transformed into free acids by an acid treatment (in $4 \mathrm{M} \mathrm{HCl}$ at $100^{\circ} \mathrm{C}$ for $4 \mathrm{hr}$ ). We tried this, but found that standard 3-hydroxyanthranilic acid and anthranilic acid were significantly destroyed by this treatment. Therefore, an alternative hydrolyzing procedure such as glucuronidase treatment must be developed to measure conjugated acids.

\section{References}

1) D. A. Bender and A. E. Bender, Nutrition Abstracts and Reviews (Series A), 56, 695 (1986).

2) B. Wilcken, J. S. Yu and D. A. Brown, Arch. Dis. Child., 52, 38 (1977)

3) T. Tada, H. Ita, Y. Wada and T. Arakawa, Tohoku J. Exp. Med., 80, 118 (1963).

4) J. Mendels, J. L. Stinnett, D. Burns and A. Frazer, Arch. Gen. Psychiatry, 32, 22 (1975).

5) C. A. Benassi, P. Benassi, G. Allegri and P. Balarin, J. Neurochem., 7, 264 (1971)

6) A. J. Greenberg and R. Ketcharm, J. Pharma. Sci.,
67, $478(1978)$.

7) K. Shibata, M. Onodera, T. Kawada and K. Iwai, $J$ Chromatogr., 430, 381 (1988).

8) K. Shibata, J. Chromatogr., 430, 376 (1988).

9) K. Shibata, T. Kawada and K. Iwai, J. Chromatogr., 422, 257 (1987).

10) K. Shibata, T. Kawada and K. Iwai, J. Chromatogr., 417, 173 (1987)

11) K. Shibata, Vitamins (Japan), 61. 599 (1987).

12) K. Shibata, T. Kawada and K. Iwai, J. Chromatogr., 424, 23 (1988).

13) K. Shibata, Agric. Biol. Chem., 52, 2973 (1988)

14) K. Shibata, Agric. Biol. Chem., 53, 1329 (1989).

15) C. O. Stevens and L. M. Henderson, J. Biol. Chem., 234, 1191 (1959).

16) C. C. Porter, I. Clark and R. H. Silber, Arch. Biochem., 18, 339 (1948).

17) L. M. Henderson, I. M. Weinstock and G. B. Ramasarma, J. Biol. Chem., 189, 19 (1951).

18) J. M. Van Der Poll, M. Vink, J. Schrijver and J. Odink, J. Chromatogr., 375, 213 (1986).

19) A. E. Michael, K. N. Drummond, D. Doeden, J. A Anderson and R. A. Good, J. Clin. Invest., 43, 1730 (1961).

20) S. L. Tompsett, Clin. Chim. Acta, 456 (1961).

21) R. J. Boucek, R. J. Boucek, Jr., V. Hlarackora and L. S. Dietrich, Biochim. Biophys. Acta, 141, 473 (1967).

22) D. R. Rose and P. A. Toseland, Clin. Chim. Acta, 17, 235 (1967).

23) M. Ghebreszabher, S. Rufini, M. G. Gastellucci and M. Lato, J. Chromatogr., 222, 191 (1981).

24) S. M. El-Zoghby, Z. A. El-Kholy, S. M. El-Sewedy and G. A. Adbel-Tawab, Acta Vitamin. Enzymol. (Milano), 32, 155 (1978).

25) S. M. El-Zoghby, Z. A. El-Kholy, A. A. Saad, M. H. Mostafa, G. A. Adbel-Tawab, N. El-Dardiri, H. El-Kabariti and A. Adbel-Rafea, Acta Vitamin. Enzymol. (Milano), 32, 167 (1978).

26) M. Mason, J. Biol. Chem., 201, 513 (1953).

27) K. Shibata and H. Matsuo, J. Nutr., 119, 896 (1989).

28) K. Wakabayashi, "Zikken Data no Seiri," Baifukan Co., Tokyo, 1984, pp. 44-57. 